\title{
A Filosofia como vocação para a liberdade*
}

MARILENA CHAUI

Senhor Diretor, Senhores Pró-R eitores,

Estimados membros componentes desta M esa,

Caros colegas, estudantes e funcionários,

Q ueridos amigos.

$\square$

M 1967, depois de defender uma dissertação de mestrado sobre M erleau-

Ponty, fui contratada como professora do Departamento de Filosofia e, em outubro daquele ano, fui enviada à França como bolsista para completar minha formação, sob a orientação de Victor Goldschmidt. Seguindo, portanto, a tradição de nosso D epartamento, eu deveria finalizar meus estudos de pósgraduação numa universidade francesa e iniciar as pesquisas de meu doutorado sob a supervisão daquele que também fora orientador de vários de meus professores brasileiros.

$\mathrm{M}$ as havia uma pedra no meio do caminho. $\mathrm{N}$ ão feriu minhas retinas cansadas, como acontecera ao poeta, mas levou-me a percorrer outras sendas. A pedra foi maio de 1968 e tudo o que ano de 1968 significou mundo afora, de Paris a Praga, de São Paulo a Berkeley, do Paralelo 27 ao Araguaia.

Para uma jovem brasileira, que deixara um país esmagado pela ditadura e no qual a esquerda apenas clandestinamente cochichava, pouco antes de ser dizimada pelo terror de Estado, a experiência de maio de 1968 permaneceria indelével, um marco no pensamento, na imaginação e na memória. Pertenço, pois, à geração de que fez seu aprendizado político nos acontecimentos da Primavera de 1968, isto é, quando uma brecha se abriu e parecia possível a reinvenção do político.

Em outubro de 1968, como um dos efeitos de maio, abriram-se as portas de uma universidade nova, uma universidade crítica na qual se reuniam e debatiam as esquerdas do mundo inteiro, dos anarquistas aos comunistas, dos socialistas aos trotskistas, dos social-democratas aos maoístas. $\mathrm{N}$ ascia a U niversidade de Vincennes. $\mathrm{N}$ o dia Primeiro de $\mathrm{O}$ utubro, ouvimos a aula inaugural proferida por $\mathrm{H}$ erbert $\mathrm{M}$ arcuse. No início da tarde, Michel Foucault iniciou um curso que antecipava o que viria a ser a M icrofísica do poder. $\mathrm{N}$ o final da tarde, D eleuze deu início ao seu curso sobre Espinosa. Eu estava em Vincennes no dia em que suas portas se abriram com a promessa da reinvenção da universidade.

* Agradecimento à homenagem feita pela Faculdade de Filosofia, Letras e Ciências $\mathrm{H}$ umanas da U SP pelo título de D outor $\mathrm{H}$ onoris $\mathrm{C}$ ausa em Filosofia, concedido à autora pela U niversidade de Paris VIII, em 20 de junho de 2003. 
Podem todos imaginar minha emoção e, mais do que isso, que tenha ficado estupefata quando a U niversidade de Paris VIII propôs e me concedeu 0 título de D outor $\mathrm{H}$ onoris C ausa em Filosofia. Como, em minha vida de estudante engajada, eu poderia imaginar que um dia voltaria a $V$ incennes para receber uma tão grande honra?

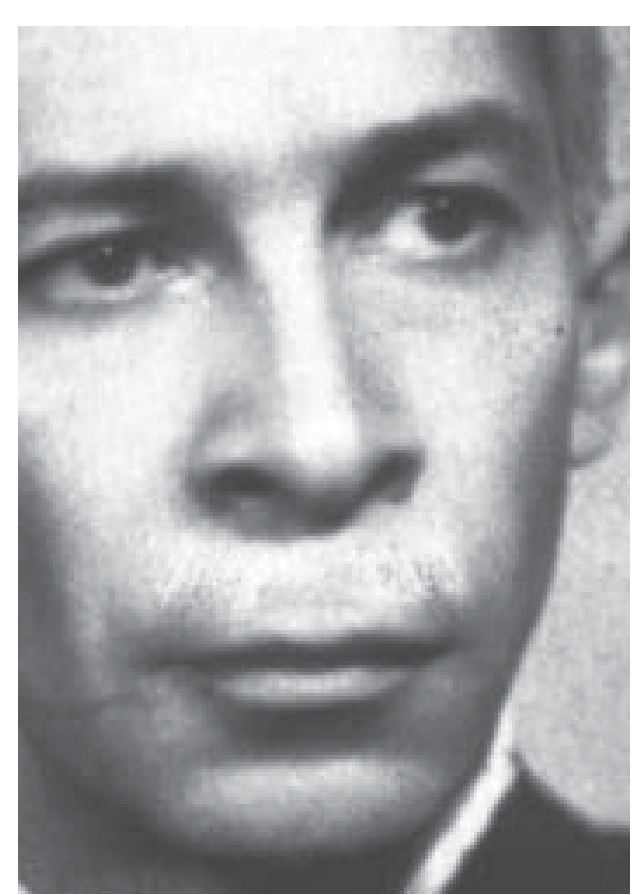

Lívio Teixeira

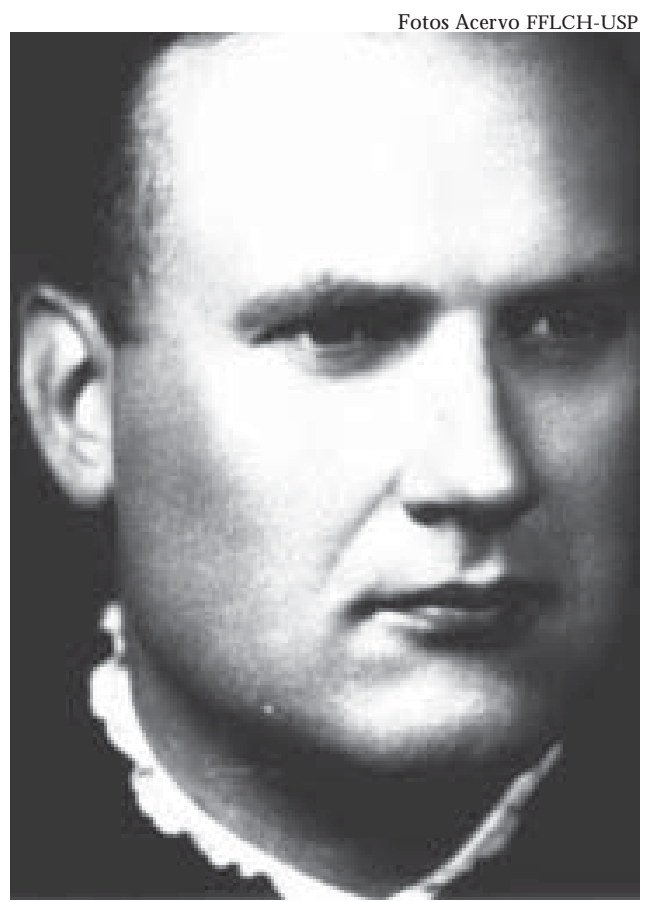

Jean Maugüé

M as não só isso. Se me sinto profundamente tocada pela honra que me fizeram é porque pertenço a um D epartamento de Filosofia instituído por uma missão francesa de que faziam parte $M$ artial Guéroult e ean M augüé, no qual fui aluna não somente de professores que foram alunos de Guéroult e de $M$ augüé, como o professor Lívio Teixeira, mas também de Gilles $\mathrm{G}$ aston $\mathrm{G}$ ranger, M ichel D ebrun e G erard Lebrun; e de um D epartamento ao qual retornou um de seus primeiros professores, Claude Lefort, que seria para mim fonte constante de inspiração e de estímulo para meu trabalho. A honraria que recebi me torna grata aos meus professores franceses, mas também faz com que eu me sinta dividida entre a surpresa e a alegria de me ver colocada ao lado deles, como se eu tivesse realizado um trabalho acadêmico que me tornasse seu par.

N este momento, não posso deixar de recordar os versos finais de Rilke nas Elegias de Duíno, quando escreve:

E nós, com a felicidade,

Q ue em nosso pensamento é uma ascensão,

Teríamos uma emoção, vizinha do espanto, que nos agarra

Q uando uma coisa feliz despenca sobre nós. 
Sei que nos dias que correm a filosofia é considerada uma profissão entre outras.

Com freqüência, tenho me perguntado por que me dediquei à filosofia.

Algumas vezes, julgo que ela me chamava desde o final de minha infância, de que tenho quatro recordações muito vívidas. A primeira delas é a de abrir um livro de minha mãe sobre filosofia da educação e em cujo primeiro capítulo cujo conteúdo esqueci inteiramente - descobri duas palavras cujo sentido não compreendi, mas que ficaram em minha mente anos a fio: Sócrates e maiêutica. Somente na adolescência, durante o ciclo colegial, quando o professor João Villalobos ministrou um curso de lógica, aprendi o que significavam essas palavras, que volta e meia eu pronunciava pelo prazer de seu som. A segunda lembrança é a de abrir um livro de meu pai sobre introdução à psicanálise e descobrir que havia algo chamado inconsciente e um fato espantoso, chamado complexo de É dipo. E videntemente, nada entendia sobre psicanálise, mas fiquei fascinada com o escândalo do que li. L embro-me de haver tentado explicar o inconsciente e o complexo de É dipo a minha amigas do colégio das freiras e de vê-las horrorizadas, dizendo-me que eu deveria ir imediatamente me confessar e comungar para me livrar do horrível pecado contido em tais pensamentos. $M$ as não me confessei. Estava encantada demais com a descoberta para renunciar a ela. A terceira lembrança situa-se por volta de meus onze anos, quando li o primeiro romance. Era Q uo Vadis. Li, reli, tresli, sabia de cor algumas passagens e particularmente o início, que me intrigara. D e fato, logo nas primeiras linhas, é narrado que Petrônio estivera num festim no palácio de $\mathrm{N}$ ero e ali discutira com L ucano e Sêneca sobre a existência ou não da alma nas mulheres. E toda vez eu me perguntava como era possível alguém fazer essa pergunta, pois era evidente que as mulheres possuem alma. $\mathrm{N}$ a época, eu não sabia que devia essa certeza ao cristianismo, mas também não sabia que a simples admissão de alma nas mulheres não Ihes havia adiantado muito. A quarta lembrança está em ter aberto um outro livro da estante de meu pai, intitulado Sociali smo utópi co e socialismo científico. Agora, algo decisivo me aparecia, mesmo que eu não tivesse compreendido quase nada do que lia. A parecia-me com clareza que a luta pela justiça, pela igual dade e pela liberdade não era uma luta moral, nascida do espírito da caridade, mas uma ação política consciente determinada pela própria história. E ra possível uma sociedade nova, justa e igualitária não simplesmente por causa de nossa indignação diante da injustiça e da desigualdade, mas porque era possível compreender suas causas e destruí-las.

O utras vezes, porém, penso que o entusiasmo pela filosofia nasceu das aulas de J oão Villalobos, que ministrou a uma classe de adolescentes de dezesseis anos um curso de lógica, em cuja primeira aula, sem qualquer aviso prévio, expôs 0 conflito entre Parmênides e H eráclito e, na segunda, a diferença entre a argumentação de Zenão e a de Górgias. Fiquei boquiaberta (e deslumbrada) com o fato de que o pensamento era capaz de pensar sobre si mesmo, que a linguagem 
podia falar de si mesma, que perceber e conhecer poderiam não ser o mesmo. 0 mundo se tornava, ao mesmo tempo, estranho, paradoxal e espantoso e a descoberta da racionalidade como problema parecia abrir um universo ilimitado no espaço e no tempo.

O utras vezes, porém, penso que fui para a filosofia quando, no final da adolescência, não podia tolerar a cultura da culpa em que fomos criados e sentia que era preciso encontrar uma outra ética em que a liberdade e a felicidade pudessem identificar-se - essa procura iria conduzir-me a Espinosa.

Talvez por causa dessas lembranças não posso considerar a filosofia uma profissão entre outras. Penso que quem busca a filosofia como forma de expressão de seu pensamento, de seus sentimentos, de seus desejos e de suas ações, decidiu-se por um modo de vida, um certo modo de interrogação e uma certa relação com a verdade, a liberdade, a justiça e a felicidade. É uma decisão existencial, como nos aparece com tanta clareza nas primeiras linhas do Tratado da emenda do intelecto, de Espinosa. Essa decisão intelectual, penso, não é possível a menos que aceitemos aquilo que M erleau-Ponty chamou de "nossa vida meditante" em busca de uma razão alargada, capaz de acolher o que a excede, o que está abaixo e acima dela própria. Essa decisão, penso também, não é possível se não admitirmos com Espinosa que pensar é a virtude própria da alma, sua excelência.

0 desejo de viver uma existência filosófica significa admitir que as questões são interiores à nossa vida e à nossa história e que elas tecem nosso pensamento e nossa ação. Significa também uma relação com o outro na forma do diálogo e, portanto, como encontro generoso, mas também como combate sem trégua. Encontro generoso porque, como nos diz Merleau-Ponty, no diálogo somos libertados de nós mesmos, descobrimos nossas palavras e nossas idéias graças à palavra e ao pensamento de outrem que não nos ameaça e sim nos leva para longe de nós mesmos para que possamos retornar a nós mesmos. M as também combate sem trégua, porque, como explica Espinosa, embora nada seja mais alegre e potente do que a amizade e a concórdia, os seres humanos são mutáveis, somos passionais e naturalmente inimigos, excitamos discórdias e sedições sob a aparência de justiça e de eqüidade. Por isso, diz ele, precisamos evitar os favores que nos escravizarão a um outro e somente os que são livres podem ser gratos uns aos outros, experimentando em sua companhia o aumento de sua força de alma, isto é, a generosidade e a liberdade.

Por pensar a filosofia como um modo de vida tecido no diálogo generoso e no combate, o combate político-filosófico me pareceu exigido num país mergulhado no terror do Estado. De fato,voltei ao Brasil em 1969, no momento que, sob o Al-5, as lutas revolucionárias estavam vencidas e a ditadura e o terror de Estado passavam à sua fase mais aguda e sombria. A Faculdade de Filosofia da rua $\mathrm{M}$ aria Antonia fora destruída pelo incêndio e as bombas do Comando de C aça aos Comunistas e fôramos jogados em barracões no campus universitário. Vivíamos no medo permanente, nunca sabendo se estaríamos vivos no dia se- 
guinte, se nossos amigos e estudantes teriam desaparecido, sido presos, torturados, mortos ou exilados. N ossos professores haviam sido cassados e éramos vigiados e censurados dentro e fora da universidade. Precisávamos praticar a filosofia como crítica do instituído, mas fazê-lo tomando como símbolo a divisa de Espinosa "C autela!". Foi sob o signo da crítica da ditadura, do autoritarismo eda ideologia da segurança nacional que, durante os anos de 1970, escrevi meu doutorado e minha livre-docência sobre Espinosa, encontrando em sua obra um pensamento que interroga seu contrário, que vai até $o$ fundo mais profundo da origem do medo e de seus efeitos: a superstição, a tirania e

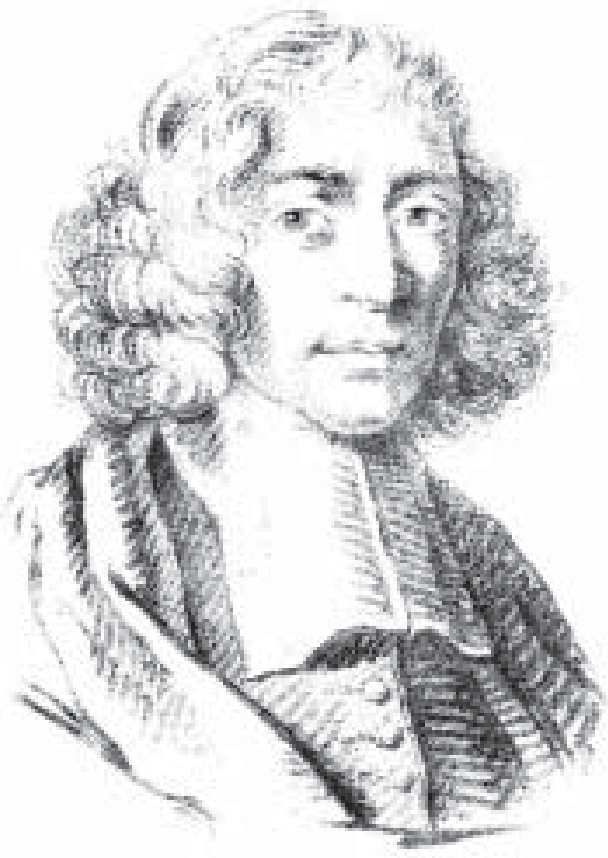

Benedictus Spinoza a servidão, cujas contradições exigem o trabalho da interrogação que se abre para a verdade e para a liberdade porque nasce do desejo de verdade e de liberdade.

A filosofia como diálogo e combate foi algo cujo sentido também aprendi no correr daqueles anos com Claude Lefort, descobrindo com ele o sentido do político como lógica do poder e não como pura relação de força e o sentido da democracia como conflito legítimo, como indeterminação e criação temporal, isto é, como invenção histórica e criação de direitos, e como recusa do poder incorporado, isto é, da identidade entre o saber, a lei e o poder.

$D$ ata também desses anos meus primeiros esforços para compreender as lutas operárias. Sob a inspiração do historiador $\mathrm{M}$ ichael $\mathrm{H}$ all, aprendi a buscar na história do movimento operário, em suas lutas e suas formas de consciência, em sua autoformação e autonomia, o lugar de onde o novo poderia efetivamente surgir. Sob o signo da história, pude compreender que o autoritarismo estrutura a sociedade brasileira na qual vigora a violência sob formas invisíveis e impal páveis, indo do machismo ao racismo, do preconceito de classe aos preconceitos sexuais, natural izando exclusões e desigualdades e escondendo sob a indivisão imaginária do verdeamarelismo as divisões sociais e as injustiças. Sob o signo da história e sob o signo da filosofia, compreendi que pode haver uma relação hipócrita entre a filosofia e política quando a primeira julga possuir as chaves da segunda e quando a segunda julga poder definir os princípios da primeira. Se participei com entusiasmo da fundação e constituição do Partido dos Trabalhadores foi justamente por ter presente, de um lado, a necessidade da crítica contínua à relação hipócrita entre filosofia e política e, de outro, por considerá-lo, à luz de meu o 
aprendizado histórico e filosófico sobre o sentido da política, uma criação histórica que foi o momento mais claro da invenção democrática no Brasil, na medida em que sua existência significou a recusa do autoritarismo social e político, que sempre forçou as classes populares a um papel subalterno.

A decisão filosófica guiou-me também, desde os anos de 1970, na luta contra a destruição da universidade pública e laica, destruição realizada sob várias formas pelo Estado brasileiro, sob os efeitos da sociedade administrada. 0 primeiro momento da destruição, ainda sob a ditadura, deu-se com a imposição da "universidade funcional", oferecida às classes médias para compensá-las pelo apoio à ditadura, oferecendo-Ihes a esperança de rápida ascensão social por meio dos diplomas universitários. Foi a universidade da massificação e do adestramento rápido de quadros para o mercado das empresas privadas instaladas com o "milagre econômico". A partir dos anos de 1990, sob os efeitos do neoliberalismo, deu-se a nova fase destrutiva com a implantação da "universidade operacional", isto é, o desaparecimento da universidade como instituição social destinada à formação e à pesquisa, surgindo em seu lugar uma organização social duplamente privatizada: de um lado, porque a serviço das empresas privadas é guiada pela lógica do mercado; de outro, porque seu modelo é a empresa privada, levandoa a viver uma vida puramente endógena, voltada para si mesma como aparelho burocrático de gestão, fragmentada internamente e fragmentan do a docência e a pesquisa. Essa universidade introduziu a idéia fantasmagórica de "produtividade acadêmica", avaliada segundo critérios quantitativos e das necessidades do mercado. Essa imagem da produção universitária tem sido uma das causas de sua degradação interna e de sua desmoralização externa, pois é uma universidade que despreza o pensamento e 0 ensino.

N essa luta contra a degradação e a desmoralização da universidade, uma idéia da docência tem sido inspiradora para mim. Ela me foi dada por meu mestre Bento Prado. Com ele, descobri que o ensino é formador quando não é transmissão de um saber do qual nós seríamos senhores, nem é uma relação entre aquele que sabe com aquele que não sabe, mas uma relação assimétrica entre aquele cuja tarefa é manter vazio o lugar do saber e aquele cujo desejo é o de buscar esse lugar. Com B ento Prado aprendi o sentido de uma existência filosófica docente formadora, pois com ele aprendi que há ensino filosófico quando o professor não se interpõe entre o estudante e 0 saber e quando o estudante se torna capaz de uma busca tal que, ao seu término, ele também queira que o lugar do saber permaneça vazio. $\mathrm{H}$ á ensino filosófico quando o estudante também se tornou professor porque o professor não é senão o signo de uma busca infinita, aberta a todos. E m outras palavras, com mestre Bento Prado descobri o sentido da liberdade que preside ensinar e aprender.

$\mathrm{H}$ á pouco, disse que o desejo de viver uma vida filosófica significa admitir que as questões são interiores à nossa vida e à nossa história. É preciso, agora, acrescentar que as questões são apenas índices ou signos da indeterminação es- 
sencial de nossa experiência e que acedemos a uma vida filosófica quando essa indeterminação, por mais apavorante que seja, nos fascina e nos arranca de nós mesmos. Assim, quando falo em vida filosófica, penso nas palavras extraordinárias escritas por $M$ erleau-Ponty no dia em que foi recebido no Collège de France, que me permito reproduzir aqui, citando o Elogio da Filosofia:

A filosofia e o ser absoluto não estão acima dos erros rivais que se opõem no século; esses erros não são erros da mesma maneira e a filosofia, que é a verdade integral, tem a tarefa de dizer o que pode integrar de cada um deles [...]. 0 absoluto filosófico não tem sede em parte alguma, nunca está alhures, mas é para ser defendido em cada acontecimento [...]. Ao final de uma reflexão que, de início, o afasta, mas para melhor fazê-lo experimentar os laços de verdade que o prendem ao mundo e à história, o filósofo encontra, não o abismo do si ou do saber absoluto, mas a imagem renovada do mundo e dele próprio plantado nela, no meio dos outros [...]. 0 filósofo é o homem que desperta e fala, e o homem contém silenciosamente os paradoxos da filosofia, porque para ser inteiramente homem, é preciso ser um pouco e pouco menos homem.

Resta, porém, explicar por que aceitei a honraria francesa e as generosas homenagens de meus colegas, amigos, estudantes e funcionários brasileiros.

U m leitor dos primeiros parágrafos do Tratado da emenda do intelecto há de se surpreender que eu as aceitasse, pois E spinosa afirma que nós nos perdemos de nós próprios e dos outros quando consideramos um bem supremo, entre outras coisas, as honras. Todavia, o leitor paciente há de esperar al guns parágrafos seguintes, quando o filósofo também afirma que as honras são boas quando as desejamos com moderação. A honra é uma paixão alegre, que fortalece nossa potência de existir, pensar e agir.

No entanto, sou eu, agora, que me pergunto por que aceitei essa honra.

Para essa indagação, possuo duas respostas, uma delas psicológica ou biográfica e uma outra, política.

Conta minha mãe, que, em 1946, visitou nossa pequena cidade interiorana um pianista polonês que deu um concerto. D epois de tocar esplendorosamente por mais de uma hora, o pianista levantou-se e indagou se havia na platéia quem tocasse piano e convidava os pianistas locais a tocar al gumas peças. E mbora houvesse no público três professoras de piano e algumas alunas adolescentes, ninguém se apresentou. Para surpresa e pavor de minha mãe, eu, com cinco anos de idade e recém-iniciada no piano, levantei-me, fui ao palco e toquei $D$ anúbio $A$ zul, numa versão simplificada. 0 que minha mãe, a platéia e o pianista jamais souberam foi o motivo de eu ter ido executar infantilmente o $D$ anúbi o $A$ zul. L onge de ser a pretensão de alguém que se julgava pianista, dirigi-me ao palco porque não pude suportar que o pianista polonês convidasse alguém para reunir-se a ele na- 
quilo que amava fazer e que ninguém se juntasse a ele, deixando-o solitário no palco. Foi o sentimento de sua enorme solidão que me levou ao piano.

Se narro esse episódio é porque, e aqui vem minha resposta política, num mundo acadêmico hegemonicamente masculino, considero intolerável a solidão das mulheres e por isso, ao ser chamada ao palco da honra, nele subi para que nele também estejam as mulheres.

N um ensaio belíssimo, chamado 0 silêncio das romanas, o helenista e romanista M oses Finley nos lembra que as mulheres de Roma não possuíam nome próprio, pois seus nomes eram apenas os de suas famílias escritos no feminino. Dessas mulheres, escreve Finley, não possuímos nada, sequer uma carta, um poema. Possuímos apenas as inscrições em suas lápides, nas quais pais, maridos e filhos dizem que foram filhas, esposas e mães extremosas e amadas. Penso que a homenagem que hoje me é feita faz parte do reconhecimento do nome próprio das mulheres, e que ao aceitá-la, contribuo para diminuir nossa solidão.

$\mathrm{N}$ um comovente ensaio, U m quarto para si, um ciclo de conferências dedicado à relação entre as mulheres e a literatura, Virgínia Woolf propõe uma ficção. I maginemos, diz ela, que Shakespeare tivesse tido uma irmã e que ela, como ele, fosse extremamente inteligente, sensível, bem dotada para as humanidades, talentosa para a poesia e para a dramaturgia. Enquanto ele recebia uma educação propícia a desenvolver seu talento, ela era treinada nos afazeres domésticos e na preparação para o casamento. Q uando ele partiu para Londres, ela deveria partir com um marido. Inconformada, fugiu também para L ondres. Ali, porém, não conseguiu publicar seus poemas nem encenar suas peças, não tinha abrigo, comida nem agasal ho para os dias de frio. $N$ uma noite de inverno, encoIhida e na mais profunda solidão, ainda jovem, morreu na neve, ignorada por todos e de todos desconhecida. E escreve Virgínia:

A irmã de Shakespeare, da qual ninguém fala, vive ainda. Ela vive em vós e em mim e em inúmeras outras mulheres que não estão presentes aqui esta noite porque estão lavando os pratos ou ninando seus filhos. M as ela vive, pois os grandes poetas não morrem jamais, são presenças eternas; apenas esperam a ocasião para aparecer entre nós em carne e osso. H oje, creio, está em vós o poder de dar essa ocasião à irmã de Shakespeare. Eis minha convicção: [...] se tivermos 150 libras de renda e um quarto só para nós, se adquirirmos 0 hábito, a liberdade e a coragem de escrever exatamente 0 que pensamos, se conseguirmos sair da sala-de-estar e ver os humanos não apenas em suas relações uns com os outros, mas também com a realidade [...], então se apresentará a ocasião para que a irmã morta de Shakespeare tome a forma humana a que teve tantas vezes de renunciar. [...] M as não há que esperar sua vinda sem esforço, sem preparação de nossa parte, sem que estejamos resolvidas a lhe oferecer um novo nascimento, a possibilidade de viver e de escrever. M as eu vos asseguro que ela virá, se trabalharmos por ela e que trabalhar assim é coisa que vale a pena. 
A honra e a homenagem que hoje tão generosamente me são feitas são 0 reconhecimento de que é possível tirar as mulheres da solidão para vê-las dar vida à irmã de Shakespeare.

M uito obrigada.

Estátua O Pensador, de A ugusteR odin (1800).

M arilena deSouza Chauí é professora titular da Faculdade de Filosofia, Letras e Ciências H umanas da U niversidade de São Paulo. É autora, entre outras, das obras 0 queé ideologia (Brasiliense), Da realidade sem mistérios ao mistério do mundo - Espinosa, Voltaire, M erleau-Ponty (Brasiliense), Seminários - 0 nacional e o popular na cultura brasileira (Brasiliense), Cultura e democracia - O discurso competente e outras falas (M oderna), I ntrodu ção à H istória da Filosofia - D os présocráti cos a A ristóteles (Companhia das L etras), Política em Espinosa (C ompanhia das L etras) e C onviteà Filosofia (Ática).

Texto recebido e aceito para publicação em 3 de setembro de 2003. 